\title{
Knowledge About Immunosuppressant
}

\section{Medication and Its Correlates in a German Kidney Transplant Population - Results of a KTx $360^{\circ}$ Substudy}

This article was published in the following Dove Press journal:

Patient Preference and Adherence

\author{
Sophie de Boer ${ }^{1,2}$ \\ Felix Klewitz $\mathbb{D}^{1,2}$ \\ Maximilian \\ Bauer-Hohmann $^{1,2}$ \\ Lena Schiffer 2,3 \\ Uwe Tegtbur ${ }^{2,4}$ \\ Lars Pape ${ }^{2,3}$ \\ Mario Schiffer $2,5,6$ \\ Martina de Zwaan (1D) ${ }^{1,2}$ \\ Mariel Nöhre ${ }^{1,2}$ \\ 'Department of Psychosomatic Medicine \\ and Psychotherapy, Hannover Medical \\ School, Hannover, Germany; ${ }^{2}$ Project \\ Kidney Transplantation $360^{\circ}\left(\mathrm{NT} \times 360^{\circ}\right)$, \\ Hannover Medical School, Hannover, \\ Germany; ${ }^{3}$ Department of Pediatric \\ Kidney, Liver and Metabolic Diseases, \\ Hannover Medical School, Hannover, \\ Germany; ${ }^{4}$ Department of Sports \\ Medicine, Hannover Medical School, \\ Hannover, Germany; ${ }^{5}$ Department of \\ Nephrology and Hypertension, \\ University Hospital Erlangen, Erlangen, \\ Germany; ' Department of Nephrology \\ and Hypertension, Hannover Medical \\ School, Hannover, Germany
}

Correspondence: Mariel Nöhre Department of Psychosomatic Medicine and Psychotherapy, Hannover Medical School, Carl-Neuberg-Strasse I, Hannover 30625, Germany

Tel +495II 5323932

Fax +49 5II 5323190

Email noehre.mariel@mh-hannover.de
Purpose: After organ transplantation, adherence to immunosuppressive medication (ISM) is crucial to prevent organ rejection. To enable adherence, patients need to be well informed about the different aspects associated with their ISM. However, literature suggests that knowledge regarding ISM is often inadequate.

Patients and Methods: In a cross-sectional study, 702 patients after kidney transplantation participating in a structured multimodal follow-up program $\left(\mathrm{KT} \times 360^{\circ}\right)$ were evaluated. We utilized a self-developed questionnaire which has been successfully used before to measure patients' knowledge about the ISM. Above that we aimed to evaluate potential associations between sociodemographic, medical, donation-specific, and psychosocial variables including adherence, levels of depression and anxiety, perceived social support, and cognitive functioning with the knowledge level.

Results: The mean age of the patients was 52.4 years, $58.1 \%$ were men, and $66.6 \%$ were living in a partnership. The mean time since transplantation was 65.1 months. On average, patients answered $70.9 \%$ of the questions correctly. The percentage of correct answers per question differed considerably (54\%-92\%). In univariate analyses, knowledge levels were positively associated with female gender, current partnership, German as first language and better cognitive functioning. However, the effect sizes were small.

Conclusion: Taking into account that the patients after KTx can be expected to answer all questions correctly as they aim at basic knowledge, an average result of $70.9 \%$ corresponds to a moderate knowledge level. Consequently, the current educational approaches do not seem to be sufficient to inform all patients adequately. Further research is necessary on how to improve health knowledge in the long term.

Keywords: health literacy, kidney transplantation, renal transplantation, adherence, immunosuppressive medication

\section{Introduction}

For patients with end-stage renal disease (ESRD), kidney transplantation (KTx) is the treatment of choice. In comparison to dialysis, KTx improves the quality of life and is associated with a lower morbidity and mortality rate. ${ }^{1}$ To secure patient and transplant survival, adherence to the immunosuppressive medication (ISM) is of utmost importance. However, nonadherence is common: Between 28\% and $52 \%$ of the patients after KTx report non-adherent behavior. $^{2-4}$ Several aspects are 
associated with non-adherence including inadequate health literacy (HL). ${ }^{4,5}$ The World Health Organization (WHO) defines HL as

cognitive and social skills which determine the motivation and ability of individuals to gain access to, understand, and use information in ways which promote and maintain good health. ${ }^{6}$

It is known that approximately one-fourth of patients with chronic kidney disease (CKD) have limited HL., ${ }^{7,8}$ One of the main elements of HL is health knowledge. ${ }^{5,9}$ It is well known that educational programs can improve health knowledge. ${ }^{10}$ However, these programs are primarily implemented in the framework of studies and therefore are accessible only for a small proportion of patients. Most patients are informed according to the standard procedure of their transplant center. These standard procedures differ significantly.

At Hannover Medical School, patients are informed about the ISM and the correct handling several times in detail. They receive information before the transplantation and again during the regular visits to the transplant outpatient clinic after KTx. Bertram et $\mathrm{al}^{11}$ investigated the knowledge level of 239 KTx patients at Hannover Medical School using a self-developed questionnaire focusing on knowledge regarding ISM. They concluded that patients, on average, answered only $70.1 \%$ of the questions correctly. This finding seems to be in line with the literature. ${ }^{12}$ Nevertheless, these results suggest that there are considerable knowledge gaps.

In our cross-sectional study, we conducted the knowledge test in a larger sample of KTx patients at different time points after KTx. The aim was to verify the results of Bertram et $\mathrm{al}^{11}$ and to get a better understanding of potential knowledge gaps in our sample of KTx patients. Another aim was to identify sociodemographic, medical, donation-specific, and psychosocial variables associated with the knowledge level.

\section{Patients and Methods}

\section{Sample Selection}

The participants were recruited within the structured posttransplant care program $\mathrm{KT} 360^{\circ}$ which is conducted in the transplant centers of Hannover Medical School and Hann. Münden in Lower Saxony, Germany. ${ }^{13}$ The study is registered in the ISRCTN registry (https://doi.org/10. 1186/ISRCTN29416382). Patients who underwent KTx in one of the two kidney transplantation centers in the
German state of Lower Saxony could be included in the $\mathrm{KT} \times 360^{\circ}$ trial. $^{13} \mathrm{~A}$ membership of the patients in a participating statutory health insurance was mandatory. Patients of all ages could be included, however for participation in this substudy patients had to be at least 17 years of age. Participants of the $\mathrm{KT} \times 360^{\circ}$ trial with an inability to speak, read, or understand the German language, with visual impairment or a known history of severe developmental delay, hindering them from filling out the questionnaires, were excluded from this substudy. Between May 2017 and July 2019, 702 participants were included in this substudy. All participants took part in a psychosocial assessment performed by a mental health professional (physician or psychologist). Additionally, all patients were asked to complete several questionnaires. The Institutional Ethics Review Board of Hannover Medical School approved the study (Number 3464-2017). All participants gave written informed consent.

\section{Instruments \\ Knowledge Test}

Patients were asked to complete a self-developed questionnaire consisting of eight multiple-choice questions concerning necessary and more specific information regarding the immunosuppressive medication (Table 2). The instrument is expert-based and has previously been used in a different smaller sample of patients after KTx. ${ }^{11}$

The questionnaire was designed to detect lack of knowledge regarding the ISM: The questions "Which of the following foods/beverages can influence your immunosuppressant blood levels?", "When are immunosuppressant blood levels measured?", "When should you take your immunosuppressants in relation to meals?" were designed to test basic knowledge of the patients regarding correct intake of immunosuppressants and potential factors interfering with through levels. This basic knowledge is necessary to avoid unintentional variations in trough levels. The questions "Which action should be taken when you forgot to take one dosage of your immunosuppressant?"; "Which action should be taken if you - after having taken your immunosuppressant - experience diarrhea or vomiting during the day?"; "Diarrhea can significantly alter cyclosporine or tacrolimus blood levels."; "While traveling immunosuppressants have to be stored in the suitcase rather than carry-on-luggage in order to maintain a cooler temperature" and "Switching between immunosuppressants from different manufactures 
(generics) is unproblematic." were designed to test if the patients have a basic knowledge how to handle different situations regarding everyday life and everyday activities. As the questions aim at basic knowledge the patient were expected to answer all questions correctly.

Some questions had more than one correct answer, and patients were encouraged to make multiple selections. Eg, in question 4, both answer 1 and answer 2 were considered to be correct, because both actions can be adequate depending on the time point the patient noticed that he or she forgot to take the medication (shortly after the regular time or several hours later). In question 3 , answer 1 and answer 4 are considered to be correct. As most patients establish a daily routine shortly after transplantation and often stick to it without changing it for years, it seems possible that those taking their medication 1 to 2 hours before meals are unaware that taking the medication 1 to 2 hours after meals is an option as well. Taking this circumstance into account, questions were judged to be answered correctly overall if patients chose at least one correct answer without choosing a wrong answer at the same time. If the patients did not tick an answer, the question was considered as incorrectly answered. This scoring is in line with Bertram et al. ${ }^{11}$ The percentage of correctly answered questions was calculated and used for further analyses.

\section{Medication Adherence Report Scale (German Version, MARS-D)}

Adherence to the ISM was measured using the German version of the Medication Adherence Report Scale (MARS-D). ${ }^{14,15}$ The self-report instrument consists of five items, which are rated on a 5-point Likert scale leading to a total score between 5 and 25 with higher scores indicating better adherence. In accordance with other studies, a score below 25 was indicative of non-adherent behavior. ${ }^{16,17}$ The MARS-D was adapted to focus exclusively on the ISM. Cronbach's $\alpha$ for the total score was 0.643 .

\section{Hospital Anxiety and Depression Scale (HADS-D)}

To assess levels of anxiety and depression, we utilized the German version of the Hospital Anxiety and Depression Scale (HADS-D). The self-report instrument consists of two subscales "depression" and "anxiety," with seven items each. It is validated to evaluate these symptoms in physically ill patients. ${ }^{18,19}$ Each item is rated between 0 and 3 , leading to a total score between 0 and 21 . Higher scores are indicative for higher levels of depression or anxiety. Cronbach's $\alpha$ was 0.860 for depression and 0.820 for anxiety.

\section{Perceived Social Support (F-SozU K7)}

The German F-SozU K7 is a questionnaire to measure perceived social support, especially aspects of practical support, emotional support, and social integration. ${ }^{20,21}$ The instrument consists of seven items rated on a 5-point Likert scale, ranging from 1 ("does not apply") to 5 ("exactly applicable"). As a result, a total score between 7 and 35 can be achieved. Higher scores are indicative of higher levels of perceived social support. In our sample, Cronbach's $\alpha$ was 0.896 .

\section{DemTect}

Cognitive functioning was evaluated using the DemTect. The DemTect is a sensitive screening instrument for mild cognitive impairment. $^{22}$ It comprises five tasks: a word list, a number transcoding task, a word fluency task, a digit span reverse, and delayed recall of the word list, focusing on different cognitive abilities. A maximum score of 18 can be reached. A score of 13 to 18 indicates ageadequate cognitive performance, a score of 9 to 12 corresponds to mild cognitive impairment, and a score of 8 or below raises the suspicion of the presence of dementia. Score transformations are age-adapted to control for age effects between participants younger than 60 years, and participants who are 60 years or older.

\section{Medical, Sociodemographic and Donation-Specific Variables}

Information on medical conditions was taken from the medical records, including the estimated glomerular filtration rate (eGFR) ${ }^{23}$ at the time of the psychosocial assessment, information on the presence of hypertension, coronary heart disease, and diabetes mellitus.

Above that, participants were asked to answer a questionnaire to collect information on sociodemographic and donation-specific variables including sex, age, partnership status, level of education $(\geq 12$ years $/<12$ years), first language, donation type (living/deceased donor), time on dialysis, and time since KTx. Wherever possible, missing data were extracted from the medical records.

\section{Statistical Analysis}

For each variable descriptive statistics (percentages, means and standard deviations, medians, and interquartile ranges) 
were calculated. We performed a Shapiro-Wilk test and a Kolmogorov-Smirnov test to evaluate data distribution. As our data were not normally distributed, we used MannWhitney- $U$ tests to compute differences in the number of correct answers on the knowledge test between two groups (sex, level of education, partnership status, cognitive functioning (DemTect cut-off), first language, and type of donation). Spearman correlations were performed for the percentage of correct answers on the knowledge tests and continuous medical, sociodemographic, and donationspecific variables. The corresponding effect size was calculated (Spearman's $r$ and eta squared $(\eta 2)$ ): Regarding $\eta 2,0.01$ expresses a small effect, 0.06 a medium, and 0.14 a large effect. A linear regression analysis was conducted with the knowledge test results as the dependent variable and variables with an association $\mathrm{p}<0.2$ in the univariate statistics as independent variables.

We used IBM $^{\circledR}$ Statistical Software Package of Social Science $\left(\right.$ SPSS $^{\circledR}$, Chicago, IL, USA) version 26 for all statistical analyses with the statistical significance set at $\mathrm{p}<0.05$.

\section{Results}

\section{Sample Characteristics}

Between May 2017 and July 2019, 702 patients participating in $\mathrm{KT} \times 360^{\circ}$ who were at least 17 years old completed the questionnaire and participated in this substudy. Information on demographic and clinical details of the participants can be found in Table 1. The mean age was 52.4 (SD 14.2) years; $58.1 \%$ of the participants were male. The majority of participants had received less than 12 years of formal education (73.9\%). Mean eGFR was $45.8 \mathrm{~mL} / \mathrm{min} / 1.73 \mathrm{~m}^{2}$ (SD 18.7), mean time on dialysis was 61.1 (SD 49.7) months. Time passed since KTx measured up to a mean of 65.1 months. The majority of KT patients had received a donor kidney from a deceased donor (70.5\%). Overall, $66.6 \%$ of the participants reported being in a partnership, and $89.2 \%$ indicated German to be their first language.

\section{Descriptive Results of the Knowledge} Test

On average, the participants answered $70.9 \%$ of the questions correctly. Results did not differ significantly between the two transplant centers (data not shown). Detailed results of the knowledge test can be found in Table 2. Overall, 569 patients $(81.1 \%)$ answered more than $50 \%$ of the questions correctly and 66 patients (9.4\%) answered all questions correctly. While there were no participants who answered all questions wrong, four patients $(0.6 \%)$ answered only one question correctly. Taking a look at the content and the answers to the individual items, some results were of particular interest: While $91.6 \%$ were aware that grapefruit might influence the immunosuppressant blood levels, only 53.7\% and $26.8 \%$ knew that St. John's wort and pomegranate might have the same effect. Regarding the effect of diarrhea on cyclosporine or tacrolimus blood levels, $11.3 \%$ were unaware that alterations might occur, and $10.2 \%$ were unable to answer this question at all. Additionally, 28.8\% indicated that it is unproblematic to switch between different immunosuppressant manufacturers.

\section{Correlates of the Knowledge Test}

Spearman correlations between the number of correct answers on the knowledge test and different continuous variables can be found in Table 3. Comparisons between dichotomous variables concerning the knowledge test are presented in Table 4.

Better knowledge regarding the immunosuppressive medication was associated with female sex, being in a partnership, better cognitive functioning and German as first language. Overall, the effect sizes were small. There was no statistically significant association between the knowledge test and age, time since transplantation, educational level, type of donation, time on dialysis, kidney function (eGFR), somatic comorbidities (diabetes mellitus, hypertension, coronary heart disease) (data not shown), level of anxiety, perceived social support and self-reported adherence.

We conducted a multiple linear regression analysis to identify independent predictors of the number of correct answers on the knowledge test (Table 5). The independent variables explained only $4.8 \%$ of the total variance of the knowledge test results. Sex, partnership status, and first language were statistically significantly associated with the percentage of correct answers on the knowledge test. The Variance Inflation Factors in the linear regression analysis were below 1.1, indicating that there was no relevant collinearity between the independent variables.

\section{Discussion}

In line with the findings of Bertram et al, ${ }^{11}$ on average, only about $70 \%$ of the questions were answered correctly. Above that, from a content-wise perspective, it became apparent that some patients were unaware of the most basic information. As the questions focus on scenarios 
Table I Patient Characteristics

\begin{tabular}{|c|c|}
\hline Patient Characteristics & $\mathrm{N}=702$ \\
\hline \multicolumn{2}{|l|}{ Age in years } \\
\hline Mean (SD) & $52.4(14.2)$ \\
\hline Median (IQR) & $54.6(20.0)$ \\
\hline Female sex, n (\%) & $294(41.9)$ \\
\hline$\geq 12$ years school attendance, $n(\%),(n=697)$ & $183(26.1)$ \\
\hline Living in a partnership, $n(\%),(n=697)$ & $464(66.6)$ \\
\hline German as first language, $n(\%),(n=64 I)$ & $572(81.5)$ \\
\hline Living donation, n (\%) & $207(29.5)$ \\
\hline \multicolumn{2}{|l|}{ Time on dialysis in months } \\
\hline Mean (SD) & $61.1(49.7)$ \\
\hline Median (IQR) & $55.5(84)$ \\
\hline \multicolumn{2}{|l|}{ Time since transplantation in months } \\
\hline Mean (SD) & $65.1(69.2)$ \\
\hline Median (IQR) & $48.6(78.2)$ \\
\hline \multicolumn{2}{|l|}{ eGFR $\left(\mathrm{mL} / \mathrm{min} / 1.73 \mathrm{~m}^{2}\right)$ at time of assessment $(\mathrm{n}=693)$} \\
\hline Mean (SD) & $45.8(18.7)$ \\
\hline Median (IQR) & $43.1(24.4)$ \\
\hline Diabetes mellitus, $\mathrm{n}(\%)$ & $123(17.5)$ \\
\hline Hypertension, n (\%) & $595(84.8)$ \\
\hline Coronary heart disease, $\mathrm{n}(\%)$ & $79(11.3)$ \\
\hline \multicolumn{2}{|l|}{ HADS-D, Anxiety score $(n=686)$} \\
\hline Mean (SD) & $5.1(3.9)$ \\
\hline Median (IQR) & $4.0(6.0)$ \\
\hline \multicolumn{2}{|l|}{ HADS-D, Depression score $(n=688)$} \\
\hline Mean (SD) & $4.3(3.9)$ \\
\hline Median (IQR) & $3.0(6.0)$ \\
\hline \multicolumn{2}{|l|}{ F-SozU K7 score $(n=687)$} \\
\hline Mean (SD) & $30.0(6.0)$ \\
\hline Median (IQR) & $32.0(8.0)$ \\
\hline \multicolumn{2}{|l|}{ MARS-D score $(n=687)$} \\
\hline Mean (SD) & $24.4(1.2)$ \\
\hline Median (IQR) & $25.0(1.0)$ \\
\hline \multicolumn{2}{|l|}{ Knowledge test \% } \\
\hline Mean (SD) & $70.9(18.0)$ \\
\hline Median (IQR) & $75.0(25.0)$ \\
\hline
\end{tabular}

Abbreviations: eGFR, estimated glomerular filtration rate; F-SozU K7, Questionnaire for Perceived Social Support; HADS-D, Hospital Anxiety and Depression Scale; IQR, interquartile range; MARS-D, Medication Adherence Report Scale; SD, standard deviation.

that are likely to occur in everyday life, this result appears even more alarming. Some questions were answered correctly by most of the participants, while others were only known to a small proportion of participants. Therefore, patients should be educated more thoroughly. However, as not all patients show the same amount of knowledge gaps, it is essential to be aware of possible risk factors associated with low knowledge levels.

First of all, women had significantly higher knowledge about ISM compared to men. This finding is in line with the results of Bertram et al. ${ }^{11}$ Taking a look at the literature information on gender differences regarding health knowledge is limited. We were able to detect a few studies focusing on knowledge regarding cardiovascular or cerebrovascular risk factors and diseases. In these studies, women seemed to be better informed in comparison to the male participants. ${ }^{24-}$ ${ }^{27}$ Nolte et $\mathrm{al}^{24}$ assumed that women are more interested in the consequences of their disease and their health in general and are, therefore, better informed.

Another important finding was that patients living in a partnership had better knowledge compared to those without a partner. It can be assumed that a partner is a person of trust who provides support in everyday life. It is not an unusual phenomenon that patients are accompanied by their partners when they have a doctor's appointment. We can hypothesize in line with Lee et $\mathrm{al}^{28}$ that the partner might influence health-related decisions and might assimilate and digest information, just like the patient. ${ }^{29}$ Other studies suggest that social contacts might be an important source of medical information. ${ }^{30}$ When looking at the concept of HL, this phenomenon is called distributed literacy by Edwards et $\mathrm{al}^{31}$ and emphasizes the positive influence of social support on HL and healthrelated behavior. Interestingly, perceived social support was not associated with knowledge regarding ISM. It is well known that perceived social support might differ from actual social support. ${ }^{21}$ We can suspect that for the majority of people, the partner might be the first person to ask for help and who might offer it at a low threshold. Therefore, living in a partnership might provide an advantage, which might lead to better health-related knowledge.

Another result worth noting is the difference in knowledge levels between patients with German as first language and those with a different native language. This result is in accordance with recent literature. ${ }^{29,32}$ While a language barrier is a prominent aspect hindering patients from acquiring sufficient knowledge or from understanding the questions on a self-rating instrument correctly, other reasons might be of importance as well. Schouten et $\mathrm{al}^{33}$ suggest that cultural differences can influence the patients' 
Table $2 \%$ of Patients Answering Each Item on the Immunosuppressant Knowledge Questionnaire (Correct Answers are Highlighted). Multiple Selections Were Allowed.

\begin{tabular}{|c|c|c|}
\hline Question & $\begin{array}{l}\% \text { of Patients } \\
\text { Choosing the } \\
\text { Answer }\end{array}$ & $\begin{array}{l}\% \text { of Patients who Answered } \\
\text { the Question Correctly* }\end{array}$ \\
\hline $\begin{array}{l}\text { 1) Which of the following foods/beverages can influence your } \\
\text { immunosuppressant blood levels? } \\
\text { - Kiwi }\end{array}$ & $4.0 \%$ & $80.2 \%$ \\
\hline - Grapefruit & $91.6 \%$ & \\
\hline $\begin{array}{l}\text { - Chocolate } \\
\text { - Coffee }\end{array}$ & $\begin{array}{l}4.6 \% \\
5.3 \%\end{array}$ & \\
\hline $\begin{array}{l}\text { - Pomegranate } \\
\text { - St. John's wort }\end{array}$ & $\begin{array}{l}26.8 \% \\
53.7 \%\end{array}$ & \\
\hline $\begin{array}{l}\text { - Banana } \\
\text { - Peppermint tea }\end{array}$ & $\begin{array}{l}7.5 \% \\
1.4 \%\end{array}$ & \\
\hline 2) When are immunosuppressant blood levels measured? & & $92.2 \%$ \\
\hline - Before intake & $93.7 \%$ & \\
\hline $\begin{array}{l}\text { - During intake } \\
\text { - After intake } \\
\text { - Independent of intake }\end{array}$ & $\begin{array}{l}0.7 \% \\
4.3 \% \\
1.7 \%\end{array}$ & \\
\hline 3) When should you take your immunosuppressants in relation to meals? & & $54.3 \%$ \\
\hline - $\mathrm{I}-2 \mathrm{~h}$ before meals & $43.4 \%$ & \\
\hline $\begin{array}{l}\text { - Directly before meals } \\
\text { - During meals }\end{array}$ & $\begin{array}{l}13.5 \% \\
16.0 \%\end{array}$ & \\
\hline - $\mathrm{I}-2 \mathrm{~h}$ after meals & $34.9 \%$ & \\
\hline - More than 2 hours after meals & $9.1 \%$ & \\
\hline $\begin{array}{l}\text { 4) Which action should be taken when you forgot to take one dosage of } \\
\text { your immunosuppressant? }\end{array}$ & & $80.8 \%$ \\
\hline $\begin{array}{l}\text { - Skip the dosage completely } \\
\text { - Quickly take the medication }\end{array}$ & $\begin{array}{l}44.3 \% \\
49.6 \%\end{array}$ & \\
\hline $\begin{array}{l}\text { - Take twice the dosage } \\
\text { - Measure blood level and decide afterward }\end{array}$ & $\begin{array}{l}0.3 \% \\
13.2 \%\end{array}$ & \\
\hline $\begin{array}{l}\text { 5) Which action should be taken if you- after having taken your } \\
\text { immunosuppressant- experience diarrhea or vomiting during the day? }\end{array}$ & & $55.3 \%$ \\
\hline - Continue immunosuppressant intake as before & $66.7 \%$ & \\
\hline $\begin{array}{l}\text { - Immediately take another dosage } \\
\text { - Take twice the dosage the next time } \\
\text { - Measure blood level and decide afterward }\end{array}$ & $\begin{array}{l}0.1 \% \\
0.9 \% \\
37.0 \%\end{array}$ & \\
\hline $\begin{array}{l}\text { 6) Diarrhea can significantly alter cyclosporine or tacrolimus blood } \\
\text { levels. }\end{array}$ & & $78.5 \%$ \\
\hline - Yes & $78.5 \%$ & \\
\hline - No & $11.3 \%$ & \\
\hline $\begin{array}{l}\text { 7) While traveling immunosuppressants have to be stored in the suitcase } \\
\text { rather than carry-on-luggage in order to maintain a cooler temperature. } \\
\text { - Yes }\end{array}$ & $28.3 \%$ & $64.5 \%$ \\
\hline
\end{tabular}

(Continued) 
Table 2 (Continued).

\begin{tabular}{|l|l|l|}
\hline Question & $\begin{array}{l}\text { \% of Patients } \\
\text { Choosing the } \\
\text { Answer }\end{array}$ & $\begin{array}{l}\text { \% of Patients who Answered } \\
\text { the Question Correctly* }\end{array}$ \\
\hline - No & $65.0 \%$ & \\
\hline $\begin{array}{l}\text { 8) Switching between immunosuppressants from different manufactures } \\
\text { (generics) is unproblematic. }\end{array}$ & $61.5 \%$ \\
\hline - Yes & $28.8 \%$ & $62.3 \%$ \\
\hline
\end{tabular}

Note: *Questions were judged to be answered correctly if patients chose at least one correct answer without choosing a wrong answer at the same time.

Table 3 Correlational Analyses of the Knowledge Test Score Using Spearman Correlations

\begin{tabular}{|l|l|}
\hline & $\begin{array}{l}\text { Knowledge Test (\% of Correctly } \\
\text { Answered Questions) }\end{array}$ \\
\hline Age (years) & $r=0.015, p=0.70$ \\
\hline $\begin{array}{l}\text { time since } \\
\text { transplantation } \\
\text { (months) }\end{array}$ & $r=-0.036, \mathrm{p}=0.34$ \\
\hline eGFR (mL/min/l.73 $\left.\mathrm{m}^{2}\right)$ & $\mathrm{r}=0.047, \mathrm{p}=0.22$ \\
\hline $\begin{array}{l}\text { HADS-D, Anxiety score } \\
(\mathrm{n}=685)\end{array}$ & $\mathrm{r}=-0.01 \mathrm{I}, \mathrm{p}=0.77$ \\
\hline $\begin{array}{l}\text { HADS-D, Depression } \\
\text { score ( } \mathrm{n}=687)\end{array}$ & $\mathrm{r}=-0.062, \mathrm{p}=0.1 \mathrm{I}$ \\
\hline $\begin{array}{l}\text { F-SozU K7 score } \\
(\mathrm{n}=686)\end{array}$ & $\mathrm{r}=0.03 \mathrm{I}, \mathrm{p}=0.42$ \\
\hline MARS score ( $\mathrm{n}=686)$ & $\mathrm{r}=-0.02 \mathrm{I}, \mathrm{p}=0.58$ \\
\hline $\begin{array}{l}\text { Time on dialysis } \\
(\mathrm{n}=690)\end{array}$ & $\mathrm{r}=-0.074, \mathrm{p}=0.05 \mathrm{I}$ \\
\hline
\end{tabular}

Abbreviations: eGFR, estimated glomerular filtration rate; F-Sozu K7, Questionnaire for Perceived Social Support; HADS-D, Hospital Anxiety and Depression Scale; MARS-D, Medication Adherence Report Scale.

behavior and interaction between patients and health-care professionals.

Furthermore, in the univariate analyses, we were able to show that better knowledge was associated with better cognitive functioning. It appears logical that reduced cognitive functioning might deteriorate the patients' ability to remember and to recall information given to them by health-care professionals. From a clinical perspective, it seems to be of utmost importance to identify these patients and to provide them with sufficient support. ${ }^{34}$
Table 4 Comparison of Knowledge Test Scores Between Dichotomous Variables

\begin{tabular}{|c|c|c|c|}
\hline & \multirow[b]{2}{*}{$\mathbf{N}$} & \multicolumn{2}{|c|}{$\begin{array}{l}\text { Knowledge Test (\% of Correctly } \\
\text { Answered Questions) }\end{array}$} \\
\hline & & Mean (SD) & Statistics U-Tests \\
\hline \multicolumn{4}{|l|}{ Sex } \\
\hline Female & 294 & $72.4(18.8)$ & $Z=-2.000, p=0.036$, \\
\hline Male & 408 & $69.8(17.4)$ & $\eta^{2}=0.006$ \\
\hline \multicolumn{4}{|l|}{ Partnership status } \\
\hline In a partnership & 464 & $72.2(17.4)$ & $Z=-2.330, p=0.02$ \\
\hline No partnership & 233 & $68.6(19.0)$ & $\eta^{2}=0.007$ \\
\hline \multicolumn{4}{|l|}{ Educational level } \\
\hline$\geq 12$ years & 183 & $71.1(17.1)$ & $Z=-0.162, p=0.87$ \\
\hline$<12$ years & 514 & $71.0(18.3)$ & \\
\hline \multicolumn{4}{|l|}{ Type of donation } \\
\hline Living donor & 207 & $72.5(17.7)$ & $Z=-1.333, p=0.18$ \\
\hline Deceased donor & 495 & $70.3(18.2)$ & \\
\hline \multicolumn{4}{|l|}{ Cognitive impairment } \\
\hline DemTect $\geq 13$ & 559 & $72.0(17.0)$ & $Z=-2.160, p=0.03$ \\
\hline DemTect $<13$ & 105 & $66.7(21.1)$ & $\eta^{2}=0.007$ \\
\hline \multicolumn{4}{|l|}{ First language } \\
\hline German & 572 & 71.7 (17.2) & $Z=-2.744, p=0.006$, \\
\hline Other & 69 & $63.9(22.8)$ & $\eta^{2}=0.011$ \\
\hline
\end{tabular}

Regarding transplant-specific outcomes, we found no statistically significant associations. Other studies reported a correlation between knowledge and a living kidney donation. Due to a more intense preparation, recipients of a living kidney donation are often better informed compared to recipients of a post-mortal kidney donation. ${ }^{10,35}$ Interestingly, and in contrast to the current literature, ${ }^{10,11}$ there was no difference between patients 
Table 5 Linear Regression Analysis

\begin{tabular}{|l|l|l|l|l|l|}
\hline Variables & $\mathbf{N}$ & $\boldsymbol{\beta}$ & $\mathbf{T}$ & $\mathbf{p}$-value & $\mathbf{R}^{\mathbf{2}}$ \\
\hline Knowledge test & 583 & & & & 0.048 \\
\hline Sex & & -0.086 & -2.083 & $\mathrm{P}=0.038$ & \\
\hline First language & & -0.113 & -2.760 & $\mathrm{P}=0.006$ & \\
\hline Partnership status & & 0.113 & 2.749 & $\mathrm{P}=0.006$ & \\
\hline Cognitive impairment & & -0.064 & -1.545 & $\mathrm{P}=0.123$ & \\
\hline $\begin{array}{l}\text { Depression (HADS- } \\
\text { D) }\end{array}$ & & -0.049 & -1.195 & $\mathrm{P}=0.233$ & \\
\hline $\begin{array}{l}\text { Time on dialysis } \\
\text { (months) }\end{array}$ & & -0.075 & $-1.83 \mathrm{I}$ & $\mathrm{P}=0.068$ & \\
\hline
\end{tabular}

Abbreviation: HADS-D, Hospital Anxiety and Depression Scale.

having received a donation from a living donor compared to those with a post-mortal organ donation. Regarding time since transplantation, our results differ from the findings of Bertram et al: ${ }^{11}$ We found no association between time since transplantation and knowledge levels. Considering the average knowledge levels of the participants, it seems evident that patients require further information independently of the particular time since transplantation.

No association was found between kidney functioning and knowledge level. We might hypothesize limited knowledge concerning important health-related information might lead to mistakes in handling the ISM, which might negatively influence kidney functioning. However, it is crucial to keep in mind that kidney functioning depends on and is influenced by a variety of factors. ${ }^{36}$ One variable known to affect kidney functioning is adherence behavior. ${ }^{37}$ However, as unintentional nonadherence might occur because of knowledge gaps, intentional nonadherence is driven by a variety of psychosocial factors. ${ }^{38}$ Indeed, knowledge levels were independent of self-reported adherence in our sample.

Several studies suggest that HL is strongly associated with the educational level, with individuals with higher education dispose of better abilities to gain HL. Even though health knowledge constitutes only a part of HL, it can be hypothesized that participants with higher educational levels have better knowledge concerning the ISM. Based on the findings of our study, however, we cannot confirm this assumption. Moreover, our results suggest that health-care professionals should be careful in making assumptions on the knowledge level of a patient based on his or her educational level.
There are some limitations to note. First of all, our knowledge test is not a validated questionnaire. Nevertheless, it has been successfully used before ${ }^{11}$ and focusses on a variety of important aspects concerning ISM. Above that, the predictor variables included in our analyses explain only a small proportion of the variance, and the effect sizes $\left(r, \eta^{2}\right)$ in the univariate analyses were small. Thus, other variables will play an important role in explaining knowledge levels. Further research is required to gain more insight.

\section{Conclusion}

In conclusion, we were able to evaluate knowledge about ISM in a large sample of German KTx patients. In line with others, we revealed, on average, a moderate knowledge level and alarming knowledge gaps in some patients. Low health knowledge was associated with the male gender, being single, German being a second language as well as cognitive impairment.

From a clinical perspective, it seems important to identify patients with several risk factors for low knowledge levels and provide them repeatedly with important information. Above that, it becomes obvious the information currently provided by the transplant center is not sufficient for a meaningful proportion of patients. However, providing extensive educational programs reaching all patients is difficult to administer. While the $\mathrm{KT} \times 360^{\circ}$ trial $^{13}$ is not an educational program, it focusses on improving graft survival and quality of life after kidney transplantation by implementing a structured posttransplant care program incorporating different elements. Thus, we will continue to evaluate health knowledge longitudinally in the participants of our study to identify changes in health knowledge over time.

\section{Abbreviations}

CKD, chronic kidney disease; eGFR, estimated glomerular filtration rate; ESRD, end-stage renal disease; F-SozU K7, Questionnaire for Perceived Social Support; HADS-D, Hospital Anxiety and Depression Scale; HL, health literacy; IQR, interquartile range; ISM, immunosuppressive medication; KTx, kidney transplantation; MARS-D, Medication Adherence Report Scale; SD, standard deviation; WHO, World Health Organisation.

\section{Data Sharing Statement}

Where patient data can be anonymized, data that underlie the results reported in this article are available on request to the corresponding author. Data are available 
beginning 6 months and ending 5 years after publication.

\section{Ethics Approval and Informed Consent}

The studies involving human participants were reviewed and approved by the Institutional Ethics Review Board of Hannover Medical School (Number 3464-2017). The patients/participants provided their written informed consent to participate in this study.

In Germany, transplantation of human organs is governed by the German Transplant Act (TPG, http://www. gesetze-im-internet.de/tpg/index.html) on "organ and tissue donation, removal and transplantation". In general, in Germany the so-called decision solution is in place, ie, the organs of a deceased person may only be retrieved if the person in question gave permission for organ donation $(\S 3$ para. 1 no. $1 \mathrm{TPG})$, eg, in the form of an organ donor card, or if the next of kin consent to the donation ( $\$ 4$ TPG). The legal principals are in line with the Declaration of Istanbul.

\section{Acknowledgments}

We thank Melanie Hartleib-Otto and Raoul Gertges for their management support. Additionally, we thank the Department of General Practice and Health Services Research and Department of Internal Medicine VI, Clinical Pharmacology and Pharmacoepidemiology, University Hospital Heidelberg, Heidelberg, Germany" for providing the translation of the MARS-D.

\section{Funding}

The study is supported by a grant the Federal Joint Committee of the Federal Republic of Germany under the number $01 \mathrm{NVF} 16009$.

\section{Disclosure}

The authors declare that the research was conducted in the absence of any commercial, financial, or other relationships that could be construed as a potential conflict of interest.

\section{References}

1. Wyld M, Morton RL, Hayen A, Howard K, Webster AC. A systematic review and meta-analysis of utility-based quality of life in chronic kidney disease treatments. PLoS Med. 2012;9(9):9. doi:10.1371/journal.pmed.1001307

2. Denhaerynck K, Dobbels F, Cleemput I, et al. Prevalence, consequences, and determinants of nonadherence in adult renal transplant patients: a literature review. Transpl Int. 2015;18(10):1121-1133. doi:10.1111/j.1432-2277.2005.00176.x
3. Pabst S, Bertram A, Zimmermann T, Schiffer M, de Zwaan M. Physician reported adherence to immunosuppressants in renal transplant patients: prevalence, agreement, and correlates. J Psychosom Res. 2015;79(5):364-371. doi:10.1016/j.jpsychores.2015.09.001

4. Belaiche S, Décaudin B, Dharancy S, Noel C, Odou P, Hazzan M. Factors relevant to medication nonadherence in kidney transplant: a systematic review. Int J Clin Pharm. 2017;39(3):582-593. doi:10.1007/s11096-017-0436-4

5. Liu C, Wang D, Liu C, et al. What is the meaning of health literacy? A systematic review and qualitative synthesis. Fam Med Community Health. 2020;8(2):e000351. doi:10.1136/fmch-2020-000351

6. World Health Organization. Track 2: health literacy and health behavior. Available from: http://www.who.int/healthpromotion/confer ences/7gchp/track2/en/. Accessed April 10, 2020.

7. Taylor DM, Fraser SDS, Bradley JA, et al. A systematic review of the prevalence and associations of limited health literacy in CKD. Clin J Am Soc Nephrol. 2017;12(7):1070-1084. doi:10.2215/CJN.12921216

8. Taylor DM, Fraser S, Dudley C, et al. Health literacy and patient outcomes in chronic kidney disease: a systematic review. Nephrol Dial Transplant. 2018;33:1545-1558. doi:10.1093/ndt/gfx293

9. Baker DW. The meaning and the measure of health literacy. $J$ Gen Intern Med. 2006;21:878-883. doi:10.1111/j.1525-1497.2006.00540.x

10. Dageforde LA, Petersen AW, Feurer ID, et al. Health literacy of living kidney donors and kidney transplant recipients. Transplantation. 2014;98(1):88-93. doi:10.1097/ TP.0000000000000027

11. Bertram A, Pabst S, Zimmermann T, Schiffer M, de Zwaan M. How can you be adherent if you don't know how? Transpl Int. 2016;29 (7):830-832. doi:10.1111/tri.12784

12. Wright JA, Wallston KA, Elasy TA, Ikizler TA, Cavanaugh KL. Development and results of a kidney disease knowledge survey given to patients with CKD. Am J Kidney Dis. 2011;57(3):387-395. doi:10.1053/j.ajkd.2010.09.018

13. Pape L, de Zwaan M, Tegtbur U, et al. The KTx360 degrees -study: A multicenter, multisectoral, multimodal, telemedicine-based follow-up care model to improve care and reduce health-care costs after kidney transplantation in children and adults. BMC Health Serv Res. 2017;17(1):587. doi:10.1186/s12913-017-2545-0

14. Horne R, Weinman J. Patients' beliefs about prescribed medicines and their role in adherence to treatment in chronic physical illness. J Psychosom Res. 1999;47(6):555-567. doi:10.1016/S0022-3999(99) 00057-4

15. Mahler C, Hermann K, Horne R, et al. Assessing reported adherence to pharmacological treatment recommendations. Translation and evaluation of the medication adherence report scale (MARS) in Germany. J Eval Clin Pract. 2010;16:574-579. doi:10.1111/j.13652753.2009.01169.x

16. Bouwman L, Eeltink CM, Visser O, Janssen JJWM, Maaskant JM. Prevalence and associated factors of medication nonadherence in hematological-oncological patients in their home situation. $B M C$ Cancer. 2017;17(1):739. doi:10.1186/s12885-017-3735-1

17. Lee CS, Tan JHM, Sankari U, Koh YLE, Tan NC. Assessing oral medication adherence among patients with type 2 diabetes mellitus treated with polytherapy in a developed Asian community: A cross-sectional study. BMJ Open. 2017;7(9):e016317. doi:10.1136/ bmjopen-2017-016317

18. Herrmann-Lingen CH, Buss U, Snaith RP. HADS-D: Hospital Anxiety and Depression Scale - German Version. Bern: Hogrefe; 1995.

19. Zigmond AS, Snaith RP. The hospital anxiety and depression scale. Acta Psychiatr Scand. 1983;67(6):361. doi:10.1111/j.16000447.1983.tb09716.x

20. Dunkel D, Antretter E, Frohlich-Walser S, Haring C. Evaluation of the short-form social support questionnaire (SOZU-K-22) in clinical and non-clinical samples. Psychother Psychosom Med Psychol. 2005;55(5):266-277. doi:10.1055/s-2004-834746 
21. Fydrich T, Sommer G, Tydecks S, Brähler E. Social support questionnaire (F-SozU): standardization of short form (K-14). Z Med Psychol. 2009;18:43-48.

22. Kalbe E, Kessler J, Calabrese P, et al. DemTect: a new, sensitive cognitive screening test to support the diagnosis of mild cognitive impairment and early dementia. Int J Geriatr Psychiatry. 2004;19 (2):136-143. doi:10.1002/gps.1042

23. Levey AS, Stevens LA. Estimating GFR using the CKD Epidemiology Collaboration (CKD-EPI) creatinine equation: more accurate GFR estimates, lower CKD prevalence estimates, and better risk predictions. Am J Kidney Dis. 2010;55(4):622-627. doi:10.1053/ j.ajkd.2010.02.337

24. Nolte CH, Rossnagel K, Jungehuelsing GJ, et al. Gender differences in knowledge of stroke in patients with atrial fibrillation. Prev Med. 2005;41(1):226-231. doi:10.1016/j.ypmed.2004.11.003

25. Andersson P, Leppert J. Men of low socioeconomic and educational level possess pronounced deficient knowledge about the risk factors related to coronary heart disease. J Cardiovasc Risk. 2001;8:371-377. doi: $10.1177 / 174182670100800606$

26. Satish S, Markides KS, Zhang D, Goodwin JS. Factors influencing unawareness of hypertension among older Mexican Americans. Prev Med. 1997;26(5):645-650. doi:10.1006/pmed.1997.0232

27. He J, Muntner P, Chen J, Roccella EJ, Streiffer RH, Whelton PK. Factors associated with hypertension control in the general population of the United States. Arch Intern Med. 2002;162(9):1051-1058. doi:10.1001/archinte.162.9.1051

28. Lee SY, Arozullah AM, Cho YI. Health literacy, social support, and health: a research agenda. Soc Sci Med. 2004;58(7):1309-1321. doi:10.1016/S0277-9536(03)00329-0

29. Dahl KG, Andersen MH, Urstad KH, Falk RS, Engebretsen E, Wahl AK. Identifying core variables associated with health literacy in kidney transplant recipients. Prog Transplant. 2020;30(1):38-47. doi:10.1177/1526924819893285

30. Sleath B, Wurst K, Lowery T. Drug information sources and antidepressant adherence. Community Ment Health J. 2003;39 (4):359-368. doi:10.1023/A:1024080410284
31. Edwards M, Wood F, Davies M, Edwards A. 'Distributed health literacy': longitudinal qualitative analysis of the roles of health literacy mediators and social networks of people living with a longterm health condition. Health Expect. 2015;18(5):1180-1193. doi:10.1111/hex.12093

32. Timmerman L, Ismail SY, Luchtenburg AE, et al. Exploring knowledge about dialysis, transplantation, and living donation among patients and their living kidney donors. Int J Behav Med. 2015;22 (5):580-589. doi:10.1007/s12529-015-9461-7

33. Schouten BC, Meeuwesen L. Cultural differences in medical communication: a review of the literature. Patient Educ Couns. 2006;64 (1-3):21-34. doi:10.1016/j.pec.2005.11.014

34. Nöhre M, Bauer-Hohmann M, Klewitz F, et al. Prevalence and correlates of cognitive impairment in kidney transplant patients using the DemTect-Results of a KTx $360^{\circ}$ substudy. Front Psychiatry. 2019;10:791. doi:10.3389/fpsyt.2019.00791

35. Chisholm-Burns MA, Spivey CA, Pickett LR. Health literacy in solid-organ transplantation: a model to improve understanding. Patient Prefer Adherence. 2018;12:2325-2338. doi:10.2147/PPA. $\mathrm{S} 183092$

36. Serón D, Fulladosa X, Moreso F. Risk factors associated with the deterioration of renal function after kidney transplantation. Kidney Int Suppl. 2005;99:113-117. doi:10.1111/j.1523-1755.2005.09921.x

37. Sellares J, de Freitas DG, Mengel M, et al. Understanding the causes of kidney transplant failure: the dominant role of antibody-mediated rejection and nonadherence. Am J Transplant. 2012;12(2):388-399. doi:10.1111/j.1600-6143.2011.03840.x

38. Griva K, Neo HLM, Vathsala A. Unintentional and intentional nonadherence to immunosuppressive medications in renal transplant recipients. Int J Clin Pharm. 2018;40(5):1234-1241. doi:10.1007/ s11096-018-0652-6
Patient Preference and Adherence

\section{Publish your work in this journal}

Patient Preference and Adherence is an international, peer-reviewed, open access journal that focusing on the growing importance of patient preference and adherence throughout the therapeutic continuum. Patient satisfaction, acceptability, quality of life, compliance, persistence and their role in developing new therapeutic modalities and compounds to optimize clinical outcomes for existing disease states are major areas of interest for the journal. This journal has been accepted for indexing on PubMed Central. The manuscript management system is completely online and includes a very quick and fair peer-review system, which is all easy to use. Visit http:// www.dovepress.com/testimonials.php to read real quotes from published authors. 